\title{
Pathologic Stage I Esophageal Squamous Cell Carcinoma AJCC v8
}

National Cancer Institute

\section{Source}

National Cancer Institute. Pathologic Stage I Esophageal Squamous Cell Carcinoma A/CC v8. NCI Thesaurus. Code C133521.

Stage I includes: IA: (T1a, NO, MO, G1, Tumor location: Any); (T 1a, NO, MO, GX, Tumor location: Any); IB: (T1a, N0, M0, G2-3, Tumor location: Any); (T1b, N0, M0, G1-3, T umor location: Any); (T1b, NO, M0, GX, Tumor location: Any); (T2, NO, MO, G1, Tumor location: Any). T1a: Tumor invades the lamina propria or muscularis mucosae. T1b: Tumor invades the submucosa. T2: Tumor invades the muscularis propria. N0: No regional lymph node metastasis. M0: No distant metastasis. G1: Well-differentiated. GX: Grade cannot be assessed. G2: Moderately differentiated. G3: Poorly differentiated, undifferentiated. (AJCC 8th ed.) 